\title{
MANATÍES Y DELFINES EN SITIOS ARQUEOLÓGICOS PRECOLOMBINOS DE CUBA
}

\author{
Osvaldo Jiménez Vázquez
}

Gabinete de Arqueología, Oficina del Historiador de La Habana, Mercaderes 15 entre Empedrado y O'Reilly, La Habana Vieja. osvaldojimenez@patrimonio.ohc.cu

\section{RESUMEN}

Se revisa el registro de los mamíferos acuáticos hallados en sitios arqueológicos precolombinos de Cuba, el cual incluye mayormente el manatí (Trichechus manatus) y en muy escasa frecuencia al delfín nariz de botella (Turciops truncatus) y otro cetáceo. Se reitera que la foca monje del Caribe (Neomonachus tropicalis) no está presente en sitios arqueológicos cubanos.

Palabras clave: Arqueología precolombina, mamíferos acuáticos, taxonomía, Cuba.

Title: Manatees and dolphins in pre-Columbian Cuban archaeological site.

\section{ABSTRACT}

The record of pre-Columbian archeological sites involving aquatic mammals is checked. It mostly includes manatee (Trichechus manatus), a very low incidence of the bottlenosed dolphin (Turciops truncatus) and other cetacean. It is reiterated that the Caribbean monk seal (Neomonachus tropicalis) is not recorded in Cuban archaeological sites.

Keywords: pre-Columbian archaeology, aquatic mammals, taxonomy, Cuba.

\section{INTRODUCCIÓN}

El medio insular y su amplia variedad de ecosistemas disponibles condicionaron los modos de vida de los aborígenes precolombinos de Cuba. De estos, el medio marino constituyó su fuente principal de recursos, en cualquier estación del año o en épocas precarias. Tanto para el aborigen recolector-cazador-pescador como para el agricultor-ceramista, la provisión obtenida del mar fue indispensable, aun habitando sitios de tierra adentro. Los estudios arqueozoológicos han mostrado el uso por el hombre de diversos organismos marinos como crustáceos, peces, moluscos, tortugas, aves y mamíferos. En Cuba, los registros arqueológicos de estos últimos son escasos, como aislados son los reportes de este grupo zoológico en aguas cubanas. Según la literatura publicada hasta el presente, los mamíferos acuáticos explotados por los aborígenes fueron el manatí (Trichechus manatus) y el delfín nariz de botella (Turciops truncatus) (Rivero, 1981; Álvarez y Vento, 1997, 2000; Vento, 2001; Pérez et al., 2004; Sueiro et al., 2010; Ramos y Pérez, 2014). La presencia de la foca monje del Caribe (Neomonachus tropicalis) en sitios arqueológicos cubanos ha sido negada con anterioridad (Jiménez-Vázquez, 2014).

\section{OBJETIVOS}

- Revisar y actualizar el registro arqueológico precolombino de manatíes (T. manatus) y cetáceos en Cuba. Asimismo, demostrar que el manatí fue el mamífero mayormente explotado en esa época. 


\section{MATERIALES Y MÉTODOS}

Se realizó una búsqueda en la bibliografía arqueológica cubana, revisando cada reporte de restos de mamíferos acuáticos, haciendo hincapié en las fuentes originales. De esta manera, se detectaron errores causados por la nociva práctica de citar fuentes de segunda y tercera mano, frecuentemente poco confiables. Se obtuvo, además, información de arqueólogos profesionales y miembros de grupos afiliados a la Sociedad Espeleológica de Cuba. Cuando fue posible, se revisaron los materiales óseos citados en la literatura. En el Anexo 1 solo se relacionan los hallazgos de materiales óseos no modificados por el hombre, artefactos como ídolos, espátulas vómicas u otros, se citan globalmente, ya que como eran bienes muy apreciados se llevaban de un lugar a otro, y su inclusión pudiera inflar artificialmente la cifra de localidades.

La escasez de colecciones osteológicas de referencia ha incidido en la comisión de desaciertos taxonómicos, tal es el caso del registro de la foca monje ( $N$. tropicalis) en Cuba, demostrado ya como incorrecto (Jiménez-Vázquez, 2014). De manatí (T. manatus) y de algunas especies de cetáceos (T. truncatus, Steno bredanensis, Neophocoena phocaenoides, Physeter catodon) se poseen algunos ejemplares en el Museo Felipe Poey, de la Universidad de La Habana. Dos osamentas incompletas de manatí se guardan en el Gabinete de Arqueología de la Oficina del Historiador de La Habana, y existe un esqueleto montado en el Museo de Historia Natural Tomás Romay, en Santiago de Cuba.

\section{RESULTADOS Y DISCUSIÓN}

\section{MANATÍ (T. manatus)}

Como se aprecia en el Anexo 1, el manatí (T. manatus) fue el mamífero acuático que más explotaron los aborígenes cubanos, sobre todo los agricultores del oriente de Cuba. Su carne les sirvió de alimento y las gruesas y compactas costillas de su osamenta fueron materia prima para la fabricación de objetos como ídolos y espátulas vómicas (Tabío y Rey, 1985; Torres, 2006; Domínguez, 2009; Borroto y Arredondo, 2011). Las espátulas vómicas, en particular, fueron objetos muy apreciados y su empleo era exclusivo de los sacerdotes o behiques taínos durante la celebración del rito de la Cohoba. Esta era una ceremonia comunal en la cual el behique o, sacerdote principal, absolvía por la nariz el polvo de la Cohoba, una planta altamente alucinógena, para luego inducirse el vómito introduciendo la espátula en la boca; así consideraba estar purificado para consultar a los dioses.

No está claro si el manatí estuvo ligado a las creencias animistas del aborigen cubano. La asociación de sus huesos a enterramientos de los apropiadores mesolíticos en sendos sitios, pudiera poseer el significado de ofrenda. Dichos restos, consistentes en una escápula y una costilla, fueron hallados en el residuario del Limonar, Cayo Caguanes, municipio de Yaguajay, provincia de Sancti Spíritus (Rivero, 1960) y en el sitio Canimar Abajo, junto al río homónimo, provincia de Matanzas (Álvarez y Vento, 1997; 2000). Se sabe que el ofrecimiento ritual era practicado por los aborígenes apropiadores, pudiendo estar compuesto el ofertorio por objetos como esferas y dagas líticas, así como algunas especies de moluscos. Por lo tanto, cabe preguntarnos si otras especies zoológicas, como el manatí, cumplirían en algunas ocasiones el papel de ofrendas o formarían parte de un festín ofrecido al muerto. Tal asociación, no obstante, pudiera tener otro sentido, pues los restos de este animal estarían allí como desechos de dieta, ya que en Cuba es muy común que los enterramientos se hayan efectuado en lugares (sobre todo cuevas) previamente utilizados para labores domésticas (Alonso, 1995).

Los agroalfareros, por su parte, llevaron la figura del manatí a sus objetos de cerámica (Torres, 2006), quien sabe si con una connotación religiosa o solo con un sentido estético. 
Respecto al hallazgo efectuado en el sitio Canimar Abajo (Fig. 1), debemos hacer una corrección. A fines de 1996, un equipo del Comité Espeleológico de la provincia de Matanzas, excavó allí el enterramiento primario de un infante de unos 12 años de edad, el cual estaba acompañado de abundantes conchas de los moluscos marinos Strombus costatus e Isognomun alatus, y un dentario de pez óseo del orden Tetradontiformes. A unos $25 \mathrm{~cm}$ del cráneo, en dirección norte, se hallaba una costilla de un mamífero grande (Álvarez y Vento, 1997, 2000). Dichos autores estimaron que la costilla pertenecía al delfín nariz de botella (T. truncatus), sin embargo, un reciente examen reveló que la identificación no es correcta, y que en realidad corresponde a un manatí ( $T$. manatus), siendo de los arcos costales próximos a la cintura escapular, los cuales son circulares en sección.

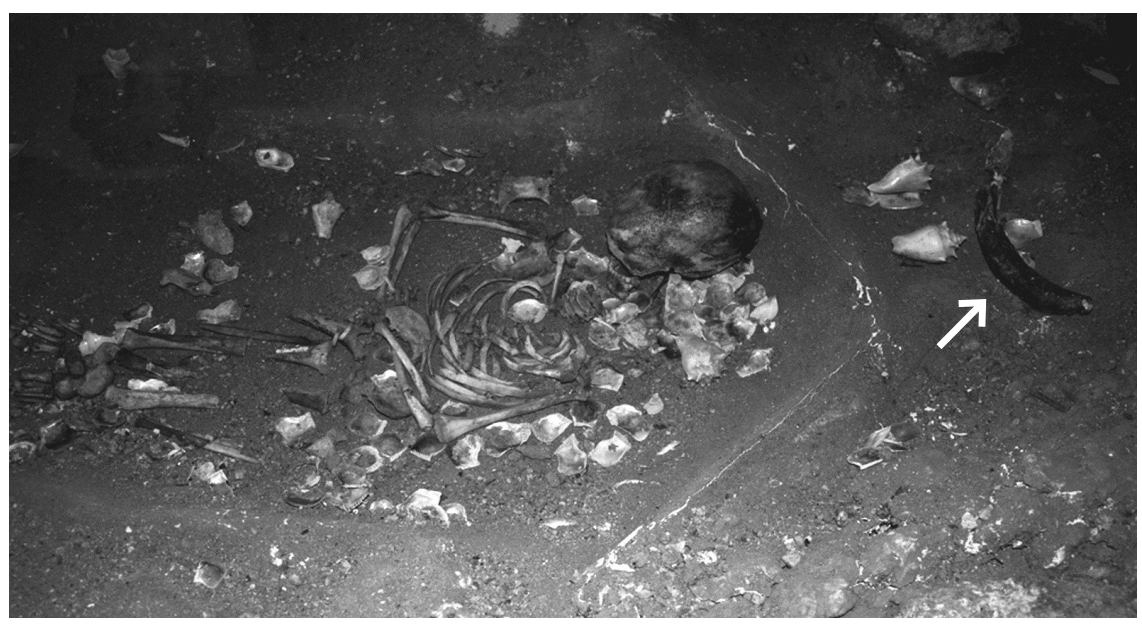

Figura 1. Entierro preagroalfarero en Canimar Abajo, costa norte de la provincia de Matanzas, Cuba, con una costilla de manatí (T. manatus) asociada. Observe la pieza a la derecha del cráneo.

Varios son los caracteres que diferencian las costillas de ambos mamíferos acuáticos. En los manatíes las primeras costillas son circulares en sección, como en el caso de la pieza que se estudia, siendo muy macizas al igual que las restantes y careciendo de cavidad medular, puesto que el animal necesita una osamenta pesada para sumergirse en aguas someras en busca de pastos marinos, su principal alimento (Allen, 1923). En cambio, el delfín nariz de botella (T. truncatus) presenta costillas aplanadas y flexibles pues precisa una estructura ósea de poco peso para alcanzar altas velocidades, y efectuar diversas piruetas.

En el pasado, la densidad poblacional y distribución del manatí fueron sin dudas superiores, parámetros ecológicos que justificaron el amplio uso que de él hicieron los aborígenes del archipiélago cubano, sobre todo aquellos asentados en la costa o próximos a ella. En los sitios de tierra adentro son muy escasos los reportes de restos de manatí.

No por casualidad fue este uno de los animales que observó Cristóbal Colón en su segundo viaje al Caribe, en 1493. En enero de ese año vio tres ejemplares cuando navegaba en La Niña, sobre las aguas del Río del Oro (río Yaguí para los aborígenes) en Santo Domingo; además, dejó testimonio de cráneos vistos en viviendas de los agricultores del oriente cubano (Las Casas, 1995). Un ejemplar de esta especie, incluso, fue mascota del Cacique Caramatex, de la isla de Santo Domingo, quien lo mantuvo en cautiverio durante 26 años en la laguna Guanabo. Este animal se nombraba Matum y había sido capturado de pequeño (Herrera en Rivero, 1966). 


\section{DELFÍN NARIZ DE BOTELLA (T. TRUNCATUS) CETÁCEO INDETERMINADO}

Los cetáceos, aunque en menor grado que los sirenios, también estuvieron relacionados con los aborígenes antillanos. En Cuba, los preagroalfareros mesolíticos utilizaron los dientes de delfín nariz de botella (T. truncatus) para confeccionar pendientes (Rivero, 1981; Sueiro et al., 2010). Estos pendientes fueron hallados en los sitios Solapa Alta, en el municipio Corralillo, provincia de Villa Clara y en Cueva Pluma, costa norte de la provincia de Matanzas.

El hallazgo de Cueva Pluma fue el de mayor interés, pues se trataba de dos pendientes manufacturados en dientes de odontoceto, los cuales formaban parte de un collar que incluía 25 cuentas de concha marina. Este collar fue encontrado en 1976 por el grupo espeleológico Humboldt, de la Sociedad Espeleológica de Cuba, junto a un entierro aborigen.

Una costilla de esta misma especie se halló junto a un cadáver aborigen en el residuario El Cocuyo, en el municipio Minas, provincia de Pinar del Río (Álvarez y Vento, 1997), asimismo, una hemimandibula de este delfín apareció en el sitio agroalfarero Los Buchillones, Punta Alegre, provincia de Ciego de Ávila (Pérez et al., 2004).

Respecto al oriente cubano, Rouse (1942) hace mención del hallazgo de huesos de una ballena indeterminada en el sitio agroalfarero Varela 3, Banes, provincia de Holguín, además figuras de delfines fueron modeladas en piezas de cerámica de esta cultura (Borroto y Arredondo, 2011; Fernández et al., 2014).

En República Dominicana, los cetáceos también formaron parte de la cosmogonía aborigen, como fue probado hace años por Renato Rímoli (1977), quien reportó el hallazgo de más de 4000 cuentas de collar en un sitio arqueológico taino en una cueva en Cabo San Rafael, provincia de La Altagracia, al sureste del país. Entre ellas se hallaban pendientes facturados en piezas dentarias de perro (Canis lupus familiaris), foca monje del Caribe (N. tropicalis) y ballena piloto (Globicephala macrorhynchus). Asimismo, Veloz Maggiolo (1980) reportó restos de cachalote (Physeter macrocephalus) en el sitio banwaroide El Porvenir, localizado en la margen occidental del río Higuamo, en San Pedro de Macorís.

Más recientemente, se descubrió un pictograma que representa una ballena, siendo la única imagen de este tipo en el Caribe insular (Torres et al., 2011). Este registro se efectuó en la Cueva de la Línea, conocida también como de Los Muñecos o del Ferrocarril, en la Bahía de San Lorenzo, cavidad esta que, además, reúne uno de los mayores conjuntos rupestres (más de 1000 diseños) para una sola estación en las Antillas. La imagen de la ballena se debe corresponder con la visión aborigen de la migración anual, entre enero y marzo, de las ballenas jorobadas (Megaptera novaeangliae), que constituye un espectáculo excepcional en la Bahía de Samaná, al noreste de la República Dominicana.

Las técnicas empleadas por el hombre primitivo cubano para la caza de mamíferos acuáticos son desconocidas, aunque se pueden esbozar algunas ideas. El manatí no debió ser de difícil captura dado que habita solo en determinadas áreas de ambientes acuáticos, como estuarios, lagunas costeras o cerca de cayos, siempre en aguas poco profundas. Se les puede encontrar en grupos o ejemplares aislados. Además, su desplazamiento es lento. El conocimiento de estas características pudo facilitar al hombre prehistórico la caza del manatí.

La obtención de una pieza de caza como el manatí debió ser un importante acontecimiento para la comunidad, ya que dispondría de un volumen de alimento grande. Un manatí caribeño adulto pesa como promedio unas 500 libras. El hombre prehistórico pudo obtener así unas 
200 libras de carne limpia y cantidades significativas de grasa, además de piel y huesos. La carne podía ser usada en el momento o conservada mediante el asado o secado al sol (MacKillop, 1985).

Según estudios etnohistóricos y etnográficos del siglo XVI, referentes a la costa caribeña mexicana, en la región Maya, los cazadores de manatíes arponeaban estos animales desde sus canoas. A los arpones iban unidas cuerdas para asegurar la pieza (MacKillop, 1985). Este autor expone que estas mismas técnicas de caza se practicaron en la misma época en otras áreas del Caribe y pudieron emplearse asimismo en tiempos prehistóricos. Es posible, asimismo, que los aborígenes agroalfareros cubanos, quienes mayor uso hicieron de esta especie, hayan empleado algún tipo de red para la captura del manatí.

En lugares interiores como el sitio agroalfarero Toma de Agua, provincia de Sancti Spiritus, localizado rio Zaza arriba, a $25 \mathrm{~km}$ de la costa sur y $45 \mathrm{~km}$ de la norte, las partes útiles del manatí debieron ser trasladadas a bordo de canoas. En estas embarcaciones también llevaron al sitio peces y tortugas grandes (Pérez et al., 2007). Las especies identificadas son la cubera (Lutjanus cyanopterus), el pargo colorado (Lutjanus campechanus) y la tortuga verde (Chelonia mydas).

La caza de cetáceos, por su parte, implicaba una complejidad que excedía la tecnología que poseían los amerindios. Los restos de estos animales han aparecido en tres ocasiones en sitios de Cuba, y es muy probable que procedan de ejemplares varados. En el archipiélago cubano se han reportado varamientos de 17 especies de cetáceos, de las 28 que habitan en el Golfo de México (Blanco, 2011).

El aprovechamiento de los cetáceos varados se conocía entre los aborígenes yámana y kawéskar, antiguos habitantes de la Tierra del Fuego, en Sudamérica (Massone y Prieto, 2005), quienes, además, almacenaban partes de éstos en agua de los pantanos o en pozas de agua salada. El varamiento permitía que las familias yámana y kawéskar se reunieran en el lugar para compartir el recurso.

Los mamíferos acuáticos, al igual que otras especies como grandes peces, moluscos y quelonios, eran procesados cerca de los sitios de caza, dado su gran peso, y las carnes trasladadas a los lugares de habitación (Pino, 1970; 1978; Newsom y Wing, 2004, Jiménez, 2005). Es esta una de la razones de la escasez de restos de mamíferos acuáticos en los sitios arqueológicos de Cuba.

\section{AGRADECIMIENTOS}

Deseo agradecer a las siguientes personas su amable ayuda: Lourdes Pérez Iglesias (Departamento de Arqueología, Holguín, Cuba), Johanset Orihuela (Florida, USA), Oscar Sánchez Arencibia (Unión de Historiadores de Cuba, Mayabeque, Cuba), Leonel Pérez Orozco (Conservador de la Ciudad de Matanzas, Cuba), Eduardo Frías Etayo (Viejo San Juan, Puerto Rico), Santiago Silva (Islas Canarias, España), Liamne Torres, Dany Morales, Alfonso P. Córdoba Medina, Ulises M. Herrera, Iriel Hernández Cobreiro, Racso Fernández Ortega (Instituto Cubano de Antropología, La Habana, Cuba), Raúl Mesa Morales, Lisette Roura (Gabinete de Arqueología, La Habana, Cuba), Alejandro Barro, Yanela García, Elier Fonseca (Facultad de Biología, Universidad de La Habana, Cuba), Jans Morffe (Instituto de Ecología y Sistemática, La Habana, Cuba. 


\section{LITERATURA CITADA}

Allen, G. M. 1923. Additional remains of the fossil Dugong of Florida. Journal of Mammalogy, 4 (4): 231-239.

Alonso, E. M. 1995. Fundamentos para la historia del Guanahatabey de Cuba. Editorial Academia, La Habana. 131 pp.

Álvarez Chávez, A., E. Vento Canosa. 1997. El delfín y su probable utilización como ofrenda en entierros aborígenes de Cuba. Revista 1861 de Espeleología y Arqueología, 1-4: 21-23, Edición Digital, www.cubaarqueologica.org.

Álvarez Chávez, A., E. Vento Canosa. 2000. El delfín como ofrenda en enterramiento aborigen de Cuba. Congreso 60 aniversario de la Sociedad Espeleológica de Cuba, Ciudad de Camagüey, del 18 al 21 de abril, resúmenes, pag. 67.

Angelbello Izquierdo, S. T., L. Delgado Ceballos. 2003. La región arqueológica Centro-Sur de Cuba. Apuntes para su estudio. El Caribe Arqueológico, 7: 16-23.

Blanco Rodríguez, M. 2011. Ballenas y delfines, 187-201. En: Mamíferos en Cuba (Eds. R. Borroto-Páez y C. A. Mancina). UPC Print, Vaasa, Finlandia. 271 pp.

Borroto Páez, R. y C. Arredondo Antúnez. 2011. Los mamíferos en el arte aborigen, 213-219. En: Mamíferos en Cuba, (Eds. R. Borroto-Páez y C. A. Mancina). UPC Print, Vaasa, Finlandia. $271 \mathrm{pp}$.

Boytel Jambú, F. 1947. El residuario de Cayo Caimanes. Revista de Arqueología y Etnología, 2 (1) 4-5: 185-191.

Chinique de Armas, Y. y R. Rodríguez Suárez. 2012. Cambios en las actividades subsistenciales de los aborígenes del sitio arqueológico Canímar Abajo, Matanzas, Cuba. Cuba Arqueológica, 5 (2): 30-48, Edición Digital, www.cubaarqueologica.org.

Domínguez, L. S. 2009. Reconstrucción histórica de los sitios agroalfareros del Centro-Sur de Cuba, 147-166. En: Particularidades arqueológicas, Ediciones Boloña, Oficina del Historiador, La Habana, 173 pp.

Fernández Ortega, R., D. Morales Valdés y L. Torres La Paz. 2014. La utilización del recurso agua. $\mathrm{Su}$ reflejo en la mitología aborigen en el actual municipio de Báguano, Holguín, Cuba. Boletín Gabinete de Arqueología, 10 (10): 74-89.

García Valdés, P. 1947. Una contribución más al estudio de la prehistoria de Cuba. Revista de Arqueología y Etnología, 2 (1) 4-5: 169-184.

Herrera Fritot, R. 1970. Exploración arqueológica inicial en Cayo Jorajuría, Matanzas. Serie Antropológica, 6: 1-20.

Jiménez-Vázquez, O. 2005. La cueva del infierno: tafonomía de un sitio arqueológico del arcaico de Cuba. Boletín Gabinete de Arqueología, 4 (4): 73-87.

Jiménez-Vázquez, O. 2014. Sobre la inexistencia de foca monje caribeña (Neomonachus tropicalis) en sitios precolombinos de Cuba. Cuba Arqueológica, 7 (2): 71-74, Edición Digital, www.cubaarqueologica.org. 
Las Casas, B. 1995. Historia de las Indias. Fondo de Cultura Económica, cuarta reimpresión, 3 t., México D.F.

Massone, M. M. y A. Prieto. 2005. Ballenas y delfines en el mundo Selk’Nam. Una aproximación etnográfica. Magallania, 33 (1): 25-35.

McKillop, H. I. 1985. Prehistoric Exploitation of the Manatee in the Maya and Circum-Caribbean Areas. World Archaeology, 16 (3): 337-353.

Morales Patiño, O., R. Herrera Fritot, F. Royo Guardia, A. González Muñoz, I. Avello y A. Leiva. 1947. Cayo Ocampo. Historia de un cayo. Revista de Arqueología y Etnología, 2 (2) 4-5: 55-123.

Navarrete, R. 1989. Arqueología Caimanes III. Editorial de Ciencias Sociales, La Habana, $55 \mathrm{pp}$.

Newson, L. A. y E. S. Wing. 2004. On land and sea. Native American uses of biological resources in the West Indies. The University of Alabama Press, Tuscaloosa, Alabama, $321 \mathrm{pp}$.

Núñez Jiménez, A. 1975. Cuba: dibujos rupestres. Ciencias Sociales, La Habana, Cuba, Industrial Gráfica S.A., Lima, Perú.

Osgood, C. B. 1942. The Ciboney Culture of Cayo Redondo, Cuba. Yale University Publications in Anthropology 25, Dpt. of Anthropology, Yale University, Ed. London Yale University Press, New Haven, 60 pp.

Pérez Iglesias, L. R., J. E. Jardines Macías y C.A. RodríguezArce. 2004. Estudio Arqueozoológico en Los Buchillones. Economía y Medio Ambiente. Archaeofauna, 13: 71- 84.

Pérez Iglesias, L. R. y E. Guarch Rodríguez. 2002. El medio ambiente precolombino en Cayo Bariay. Una perspectiva arqueológica. Ciencias Holguín, 8: 1-9, Edición Digital, www. ciencias.holguin.cu.

Pérez Jiménez, R., O. Álvarez de la Paz, S. Silva García y M. E. Rodríguez Matamoros. 2007. Arqueología aborigen del sitio Toma de Agua. Ediciones Luminaria, Sancti Spíritus, 109 pp.

Pino Rodríguez, M. 1970. La dieta de los aborígenes de Cueva Funche, Guanahacabibes, Pinar del Río, Cuba. Tercera parte. Serie Carsológica y Espeleológica, 12: 1-29.

Ramos, E. y L. Pérez Iglesias. 2014. Zooarchaeological evidence on the utilization of aquatic mammals in Northern South America and Caribbean: A contribution to long-term biological conservation. En: Neotropical and Caribbean Aquatic Mammals. Perspectives from an Archaeology and Conservation Biology. S Muñoz, C Götz and E. Ramos Editors. Nova Publisher. New York.

Rimoli, R. 1977. Nuevas citas para mamíferos precolombinos de la Hispaniola. Cuadernos CENDIA, 259: 1-15.

Rivero de la Calle, M. 1960. Caguanes: Nueva zona arqueológica de Cuba. Universidad Central de Las Villas, Santa Clara, 88 pp. 
Rivero de la Calle, M. 1966. Las culturas aborígenes de Cuba. Editora Universitaria, La Habana, $194 \mathrm{pp}$.

Rivero de la Calle, M. 1981. Pendientes aborígenes cubanos. Revista de la Biblioteca Nacional José Martí, 23 (1): 9-59.

Rodríguez-Ferrer, M. 1876. Naturaleza y civilización de la grandiosa isla de Cuba. Imprenta de J. Noguera a cargo de M. Martínez, calle de Bordadores, no. 7, Madrid, 786 pp.

Rouse, I. 1942. Archaeology of the Maniabon Hills. Yale University Publications, New Haven, $184 \mathrm{pp}$.

Sueiro Garra, A., R. Villavicencio Finalé, Lorenzo Morales Santos. 2010. Arqueofauna del sitio Solapa Alta, El Charcón. III Coloquio Internacional de Arqueología, X Conferencia Internacional de Antropología, La Habana, Memorias (DVD).

Tabío, E. E, y E. Rey. 1985. Prehistoria de Cuba. Editorial de Ciencias Sociales, La Habana, $234 \mathrm{pp}$.

Torres Etayo, D. 2006. Tainos: mitos y realidades de un pueblo sin rostro. Editorial Asesor Pedagógico, S.A. de C.V., México, D. F., 119 pp.

Torres La Paz, L. y C. Arredondo Antúnez. 2011. Piezas esqueléticas diagnósticas en mamíferos del sitio arqueológico Canimar Abajo, Matanzas, Cuba. Convención Internacional Anthropos 2011, Palacio de Convenciones, La Habana, 14-18 de marzo.

Torres La Paz, L., D. A. Gutiérrez Calvache, J. B. González Tendero, R. Fernández Ortega y C. Tavarez María. 2011. Reflexiones sobre el posible papel de las ballenas en los modos de vida precolombinos del Caribe insular, República Dominicana, un caso ejemplo. Cuba arqueológica, 10: 14-24, Edición Digital, www.cubaarqueologica.org.

Utset, B. (s/f). Notas de exploraciones. Archivo del Dpto. de Arqueología, Instituto Cubano de Antropología (inédito).

Veloz M., M. 1980. Las sociedades arcaicas de Santo Domingo. Co-ediciones Museo del Hombre Dominicano y Fundación García Arévalo. Santo Domingo.

\section{ANEXO 1. SITIOS ARQUEOLÓGICOS DE CUBA DONDE SE HAN ENCONTRADO RESTOS DE MANATÍ (T. MANATUS).}

1-Cayo Bariay, Punta de Gato, municipio Rafael Freyre, provincia de Holguín, agroalfarero, 1300-1460 d C. Costillas (Pérez y Guarch, 2002; Ramos y Pérez, 2014).

2-Esterito, municipio Banes, provincia de Holguín, agroalfarero, 870-1513 d C. No se indica tipo de resto (Ramos y Pérez, 2014).

3-San Antonio, municipio Gibara, provincia de Holguín, agroalfarero, 870-1513 d C. Costillas (Ramos y Pérez, 2014). 
4-Corinthia III, municipio Frank País, provincia de Holguín, apropiador protoagrícola, 987 a C-1313 d C. Costillas (Ramos y Pérez, 2014).

5-La Bermeja, municipio Manzanillo, agroalfarero. No se indica tipo de resto (Rodríguez-Ferrer, 1876).

6-Corrales de Ojo del Toro, municipio Pilón, provincia de Granma, agroalfarero, 870-1513 d C. No se indica tipo de resto (Ramos y Pérez, 2014).

7-El Carnero, municipio Río Cauto, provincia de Granma, agroalfarero, 870-1513 d C. No se indica tipo de resto (Ramos y Pérez, 2014).

8-Sabana la Mar, también conocido como Jutía o Hutía, municipio Río Cauto, provincia de Granma, apropiador mesolítico. No se indica tipo de resto (Utset, s/f).

9-Caimanes II, Cayo Caimanes, municipio Santiago de Cuba, provincia Santiago de Cuba, agroalfarero, 870-1513 d C. No se indica tipo de resto (Boytel, 1947; Ramos y Pérez, 2014).

10-Caimanes III, Cayo Caimanes, municipio Santiago de Cuba, provincia Santiago de Cuba, apropiador protoagrícola, 987 a C-1313 d C. Tres fragmentos de huesos, uno es una costilla (Navarrete, 1989).

11-Cayo Damas, municipio Chivirico, provincia de Santiago de Cuba, agroalfarero, 870-1513 d C. No se indica tipo de resto (Ramos y Pérez, 2014).

12-Victoria I, municipio Vertientes, provincia de Camagüey, agroalfarero, 1987 a C-1513 d C. No se indica tipo de resto (Ramos y Pérez, 2014).

13-Los Buchillones, Punta Alegre, municipio Chambas, provincia de Ciego de Ávila, agroalfarero, 1200-1600 d C. Costillas de manatí (Pérez et al., 2004).

14-Toma de agua, municipio La Sierpe, provincia de Sancti Spíritus, agroalfarero, 870-1513 d C. Costilla (Pérez et al., 2007; Ramos y Pérez, 2014).

15-Cayo Lucas, municipio de Yaguajay, provincia de Sancti Spíritus, agroalfarero, 870-1513 d C. No se indica tipo de resto (Ramos y Pérez, 2014).

16-Residuario del Limonar, Cayo Caguanes, municipio de Yaguajay, provincia de Sancti Spíritus, apropiador mesolítico. Escápula, este hueso estaba mezclado con restos de dieta como moluscos, cangrejos, jicoteas aves, jutías, etc., los cuales aparecieron próximos a la zona torácica de un cadáver aborigen, quizás como ofrenda (Rivero, 1960).

17-Cueva del Manatí, Cayo Caguanes, municipio de Yaguajay, provincia de Sancti Spíritus, apropiador mesolítico. Costilla (Rivero, 1960).

18-Cayo Carenas, municipio Cienfuegos, bahía de Cienfuegos, provincia de Cienfuegos, agroalfarero, 870-1513 d C. No se indica tipo de resto (Ramos y Pérez, 2014).

19-Cayo Ocampo, municipio Cienfuegos, provincia de Cienfuegos, agroalfarero. Costilla (Morales et al., 1947).

20-Rancho Club, municipio Cienfuegos, provincia de Cienfuegos, agroalfarero. No se indica tipo de resto (Angelbello y Delgado, 2003). 
21-Cayo Jorajuría, municipio Martí, provincia de Matanzas, apropiador protoagricola. Costilla (Herrera, 1970).

22-Canimar Abajo, municipio Matanzas, provincia de Matanzas, apropiador mesolítico, 4000 a C-1300 d C. Costilla y molares (Álvarez y Vento, 1997; 2000; Torres y Arredondo, 2011; Chinique y Rodríguez, 2012).

23-Cueva del Agua, San José de las Lajas, provincia de Mayabeque, apropiador mesolítico. Costilla (Jorge Garcell, com pers., 2014).

24-Tasajera I, municipio Nueva Paz, provincia de Mayabeque, agroalfarero, 870-1513 d C. No se indica tipo de resto (Ramos y Pérez, 2014).

25-Río del Medio (El Tejar), Nombre de Dios, municipio Minas, provincia Pinar del Río, apropiador mesolítico. Costilla (García, 1947).

26-Asiento Carapachibey, Isla de la Juventud, apropiador mesolítico, 1987 a C-1513 d C. No se indica tipo de resto (Ramos y Pérez, 2014).

27-Residuario frente a la Cueva número uno, Punta del Este, Isla de la Juventud, apropiador mesolítico. No se indica tipo de resto (Núñez, 1975).

28-Cayo Redondo, bahía de Guadiana, municipio Sandino, provincia de Pinar del Río, apropiador mesolítico. No se indica tipo de resto (Osgood, 1942).

\section{ANEXO 2. SITIOS ARQUEOLÓGICOS DE CUBA DONDE SE HAN ENCONTRADO RESTOS DE DELFÍN NARIZ DE BOTELLA (T. TRUNCATUS) O DE CETÁCEOS INDETERMINADOS.}

1-Varela 3, Banes, provincia de Holguín, agroalfarero, 870-1513 d C. Huesos de ballena (Rouse, 1942; Ramos y Pérez, 2014).

2-Los Buchillones, Punta Alegre, municipio Chambas, provincia de Ciego de Ávila, agroalfarero, 1200-1600 d C. Rama mandibular (Pérez et al., 2004).

3-Solapa Alta, El Charcón, municipio Corralillo, provincia de Villa Clara, apropiador mesolítico. Pendiente elaborado en una pieza dentaria (Sueiro et al., 2010).

4-Salón del Sol, Caverna Pluma, Cumbre Alta, municipio de Matanzas, provincia de Matanzas, apropiador mesolítico, 1987 a C-1513 d C. Dos pendientes elaborados en dientes (Rivero, 1981).

5-El Cocuyo, Biajaca, municipio Minas, provincia de Pinar del Río, apropiador mesolítico. Costilla (Álvarez y Vento, 1997). 